\title{
Antifeedant activity of red clover root isoflavonoids on Hylastinus obscurus
}

\author{
Andrés Quiroz ${ }^{1,2 *}$, Loreto Mendez ${ }^{1,2}$, Ana Mutis ${ }^{1,2}$, Emilio Hormazabal ${ }^{1,2}$, Fernando Ortega $^{3}$, \\ Michael A. Birkett ${ }^{4}$ and Leonardo Parra ${ }^{1,2}$
}

${ }^{1}$ Laboratorio de Química Ecológica, Departamento de Ciencias Químicas y Recursos Naturales, Universidad de La Frontera, Av. Francisco Salazar 01145, Temuco, Chile. ${ }^{2}$ Centro de Investigación Biotecnológica Aplicada al Medio Ambiente (CIBAMA), Universidad de La Frontera, Av. Francisco Salazar 01145, Temuco, Chile. ${ }^{3}$ Instituto de Investigaciones Agropecuarias, Centro Regional de Investigación Carillanca, Temuco, Chile. ${ }^{4}$ Biological Chemistry and Crop Protection Department, Rothamsted Research, Harpenden, AL5 2JQ, United Kingdom.*Corresponding author: andres.quiroz@ufrontera.cl

\begin{abstract}
In the last decade, there has been increasing interest in investigating the impact of flavonoids on insects, specifically for pest control. In this study, we investigated the impact of isoflavonoids upon the feeding behavior of the clover root borer, Hylastinus obscurus Marsham (Coleoptera: Curculionidae), which is one of the most serious global pests associated with red clover, Trifolium pratense L. Four aglycones isoflavonoids: genistein (1), formononetin (2), daidzein (3) and biochanin A (4) were isolated and identified by HPLC, from roots of two Chilean red clover cultivars. The first two compounds, formononetin (2) and genistein (1), showed high feeding deterrent activity when they were evaluated in artificial diets. This antifeedant effect of isoflavones on feeding behavior of $H$. obscurus suggests that they are responsible for a decreasedin insect weight gain as compared with the control. This information could be useful respectively, to farmers and researcher to produce and create plants resistant to curculionid.
\end{abstract}

Keywords: Trifolium pratense, Hylastinus obscurus, isoflavonoids, antifeedant 


\section{Introduction}

The red clover root borer, Hylastinus obscurus Marsham (Coleoptera: Curculionidae), is one of the most serious global pests associated with red clover, Trifolium pratense L. (Fabaceae) (Steiner and Alderman, 2003). Both larval and adult stages feed on the roots, causing weakening and subsequent death of plants (Aguilera et al., 1996). An average of $1.5 \mathrm{H}$. obscurus per plant can cause $5.5 \%$ reduction in forage yield in 2-3 year-old pastures and infestation levels can reach $70 \%$ to $100 \%$ (Aguilera et al., 1996).

To date, chemical control of $\mathrm{H}$. obscurus has been unsuccessful (Aguilera et al., 1996), and biological control has not been explored. Therefore, alternative strategies for controlling H. obscurus are a high priority for red clover producers. One such approach is the development of new pest-resistant red clover cultivars, and in Chile, new cultivars have been developed through polycross cycles and half-sib family evaluation, resulting in the creation of 10 synthetic lines, two of which have become registered varieties (Ortega et $a l ., 2014)$. Because this process is based on the use of individual red clover plants that survive $H$. obscurus attack for more than four seasons, it is proposed that the new lines could have developed resistance to $H$. obscurus through the production of secondary metabolites that are deleterious to the pest.

Several authors have studied plant secondary metabolites present in the roots of red clover and their effect on H. obscurus behavior. Results to date suggest that there is strong chemical communication between $T$. pretense and H. obscurus, ie, secondary metabolites present in the roots can elicit either attractant or repellent behaviour (Quiroz et al., 2005; Tapia et al., 2005, 2007; Alarcón et al., 2010; Manosalva et al., 2011). Furthermore, plant-produced isoflavonoids act as phytoalexins and also as insect feeding deterrents (Sutherland et al., 1980) have been shown to play a role in Trifolium - pest interactions eg the isoflavones formononetin, genistein, and biochanin A, present in the leaves of $T$. subterraneum L. exhibit deterrent activity on the red-legged earth mite Halotydeus destructor (Tucker) (Acari: Penthaleidae) (Wang et al., 1998). Specifically, the accumulation of the isoflavonoid formononetin in the roots of resistant white clover is believed to exhibit a defensive role on the stem nematode Ditylenchus dipsaci (Cook et al., 1995), whilst the presence of formononetin in red clover may act as a deterrent against adult weevils, Sitona lepidus (Gyllenhal) (Coleoptera: Curculionidae) Gerard et al., (2005).

Following previous reports of the role of red clover secondary metabolites in mediating $H$. obscurus behavior, and the implicated role of isoflavonoids in modifying the feeding of pests on white and red clover, the aims of this study were; a) to identify and quantify the isoflavonoids present in red clover roots, b) to establish a qualitative and quantitative comparison of isoflavonoids content between two Chilean red clover cultivars with different levels of persistence and c) to evaluate the antifeedant responses of $H$. obscurus elicited by the identified isoflavonoids. Establishing a role for these secondary metabolites in the resistance of red clover cultivars to H. obscurus could provide the basis for the generation of new pest-resistant cultivars.

\section{Materials and Methods}

\subsection{Plant material}

Two red clover (Trifolium pratense L.) cultivars, Quiñequeli INIA and Superqueli INIA with low and high persistence respectively, were collected at 
INIA-Carillanca (La Araucanía, Chile). These plants were established in September 2014 under irrigated conditions at a seeding rate of $15 \mathrm{~kg} \mathrm{ha}^{-1}$. The cultivars were distributed in a randomized complete block with three replicates. Each plot size was 1.8 x $7 \mathrm{~m}$. Fertilization consisted of $150 \mathrm{~kg}$ of $\mathrm{P}_{2} \mathrm{O}_{5} \mathrm{ha}^{-1}$ and $100 \mathrm{~kg}$ of $\mathrm{K}_{2} \mathrm{O} \mathrm{ha}^{-1}$. Weed control was performed manually and no herbicides were applied. The whole plants were sampled in October 2015 with a sufficient amount of soil to avoid root damage.

\subsection{Insects}

The methodology used for the insect collection was based on the method described by Manosalva et al., (2011). Adult H. obscurus were collected daily from 3-year-old red clover plants (cv. Quiñequeli INIA) located at INIA-Carillanca. The insects were gently removed from the roots and were maintained in Petri dishes $\left(4^{\circ} \mathrm{C}\right)$ with pieces of red clover roots $(\mathrm{cv}$. Quiñequeli INIA). The insects were deprived of food $24 \mathrm{~h}$ before each feeding assay. Prior to each test, insects that were able to walk were selected and used for the feeding assay.

\subsection{Chemicals}

Isoflavones: genistein (1), formononetin (2), daidzein (3) and biochanin A (4) were purchased from Sigma-Aldrich, Chile and solvents from Merck, Chile.

\subsection{Isoflavonoid extraction and analysis by high performance liquid chromatography (HPLC)}

Red clover root tissue $(20 \mathrm{mg}$ ) was lyophilized, milled and extracted with $80 \% \mathrm{MeOH}(2.0 \mathrm{~mL})$ for $16 \mathrm{~h}$ using an orbital shaker in dark at room temperature to obtain a polar fraction of isoflavonoids. The extract was spun down by centrifugation at 3,000 rpm for $1 \mathrm{~h}$ and the supernatant evaporated under stream of nitrogen to dryness. The dried residue was suspended in $300 \mu \mathrm{L}$ of $45 \%$ methanol (Farag et al., 2007). The identification and quantification of isoflavonoids in root extracts was performed using a HPLC method, reported by Franke et al., (1994), with modifications. Samples $(20 \mu \mathrm{L})$ were injected into a Shimadzu HPLC (LC20A Prominence, Kyoto, Japan) equipped with a C-18 column ( 300 x $4.6 \mathrm{~mm}$ I.D.; particle size $5 \mu \mathrm{m}$ ) was eluted with a mobile phase composed of acetic acid: water $(1: 9 \mathrm{v} / \mathrm{v})$ as solvent $\mathrm{A}$ and acetonitrile as solvent $\mathrm{B}$ at a flow rate of $1 \mathrm{~mL} \mathrm{~min}$. The following gradient, which is expressed as the percentage of solvent B, was used: $0 \mathrm{~min}, 23 \% \mathrm{~B}$; 0-8 $\mathrm{min}, 70 \% \mathrm{~B}$; and $8-16 \mathrm{~min}, 23 \% \mathrm{~B}$. The detection was performed at the preferred wavelength of $260 \mathrm{~nm}$. The standard solutions for the calibration curve were prepared using a mixture of all isoflavonoids (Table 1) ranging in concentration from 0.5 to $15 \mathrm{ppm}$.

\subsection{No-choice feeding (antifeedant) assays}

Antifeedant experiments (no-choice feeding assays) with adult $H$. obscurus were carried out using an artificial diet according to Faccoli and Schlyter (2007). Approximately $500 \mu \mathrm{L}$ of the diet, composed of $87.6 \%$ water, $2 \%$ cellulose, $2.6 \%$ glucose, $4.3 \%$ starch and $3.5 \%$ agar, was placed into transparent Eppendorf tubes (10 $\mathrm{mm}$ diameter x $35 \mathrm{~mm}$ length). Then, $10 \mu \mathrm{L}$ of ethanolic solutions of the identified isoflavonoid aglycones, at different concentration, maximum, minimum and two intermediates (Table 1), were added separately, ensuring homogeneous distribution of the solution in the whole diet along the tube. The Eppendorf tube was kept open in a vertical position for $30 \mathrm{~min}$ at $21^{\circ} \mathrm{C}$ for ventilation, thus allowing the solvent to completely evaporate. Subsequently, a pre-weighed H. obscurus (iw) was introduced into each tube, which was then closed 
with a plastic cap of Eppendorf tube. The insect was allowed to feed on the diet in the vertical tube for $5 \mathrm{~d}$ under darkness at room temperature. After this period, the insects were removed from the tubes and weighed again (fw). Each dose was tested individually on 20 adults. Moreover, 20 adults feeding in tubes containing only artificial diet were used as a control and each insect was used only once. The feeding performance was evaluated by the weight increase (\%), where: weight increase $(\%)=((\mathrm{fw}-\mathrm{iw}) / \mathrm{fw}) \times 100($ Toledo et al., 2014) .

Table 1. Quantification ( $\mathrm{mg} \mathrm{g}^{-1}$ dry matter) by HPLC-UV of the isoflavonoids presents in the polar fractions obtained from the roots of Quiñequeli INIA and Superqueli INIA.

\begin{tabular}{cccc}
\hline $\begin{array}{c}\text { Retention time } \\
(\text { min })\end{array}$ & Compound & Quiñequeli INIA & Superqueli INIA \\
\hline 8.50 & Daidzein & $1.043 \pm 0.22$ & $1.025 \pm 0.27$ \\
11.01 & Genistein & $0.494 \pm 0.11$ & $0.651 \pm 0.08$ \\
12.75 & Formononetin & $0.098 \pm 0.01$ & $0.195 \pm 0.01 *$ \\
20.6 & Biochanin A & $1.575 \pm 0.24$ & $2.668 \pm 0.23 *$ \\
\hline
\end{tabular}

Asterisk indicates significant differences in the concentration of flavonoid between cultivars by the non-parametric MannWhitney test $(p<0.05)$.

\subsection{Statistical analysis}

Non-parametric tests were used because the data did not conform to the statistical requirements of normality and homoscedasticity. The total isoflavonoid data in both cultivars were analyzed using the Wilcoxon signed rank test for paired samples $(p<0.05)$. Differences among isoflavonoids by cultivar were analyzed by Mann-Whitney test $(p<0.05)$. Results from feeding bioassays were analyzed by Friedman and Kruskall-Wallis test $(p<0.05)$ followed by the ConoverInman test (Conover, 1999).

\section{Results}

\subsection{Identification and quantification of isoflavonoids}

The analysis of isoflavonoids from $T$. pratense revealed the presence of four aglycones in the polar extracts of both Quiñequeli INIA and Superqueli
INIA. Aglycones identified were diadzein, genistein, formononentin and biochanine A (Table 1, Figure 1).

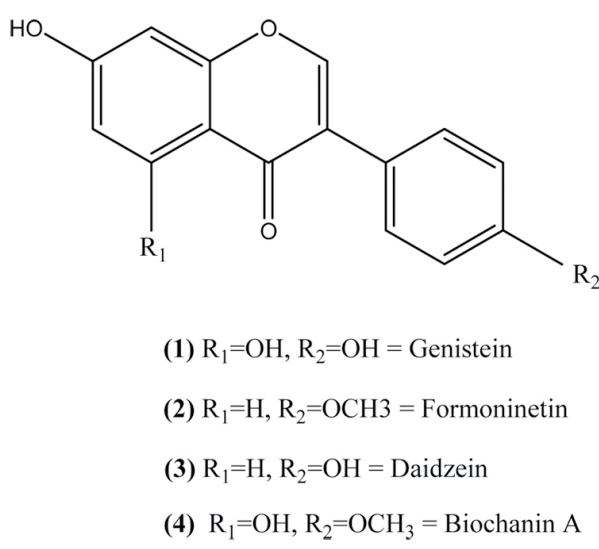

Figure 1. Structures of isoflavonoid from Trifolium pratense: (1) genistein, (2) formononetin and (3) daidzein. (4) biochanin A. 
Levels ( $\mathrm{mg} \mathrm{g}^{-1}$ of dry matter) of genistein $(0.494 \pm 0.11$ vs $0.651 \pm 0.08)$ and daidzein $(1.043 \pm 0.22$ vs 1.025 \pm 0.27 ) were not significantly different between cultivars $(p>0.05)$. Levels of formononetin were significantly higher in Superqueli INIA $(0.195 \pm 0.01)$ than Quiñequeli INIA $(0.098 \pm 0.01)(p<0.05)$. Significant differences in the level of biochanin A were detected between the cultivars $(1.575 \pm 0.24$ vs $2.668 \pm 0.23)$ ( $p$ $<0.05$ ). Moreover, there were significant differences when the averages of the four isoflavonoids was compared between both cultivars evaluated, with the level being greater in Superqueli INIA $(1.135 \pm 0.54)$ than Quiñequeli INIA $(0.802 \pm 0.32)(\mathrm{p}=0.0261)$.

\subsection{Feeding bioassays}

Antifeedant bioassays using an artificial diet indicated that the addition of formononetin and genistein to the diet clearly affected the feeding behavior of H. obscurus, compared to the diet controls (Figure 2). Weight increase data demonstrated that whereas control weights steadily increased $(3.45 \pm 1.14 \%)$, individuals with doses of 0.098 to $0.195 \mathrm{mg} / \mathrm{g}$ of formononetin had lower weight gains (Figure 2A). The aglycone genistein elicited a similar antifeedant behavior at all doses, with a decreased in insect weight gain from $2.56 \pm$ $0.95 \%$ (control) to $-3.71 \pm 1.53 \%(0.651 \mathrm{mg} / \mathrm{g})(\mathrm{p}=$ 0.0013 , Figure 2B). By contrast, daidzein revealed a significant feeding-preference activity $(\mathrm{p}=0.0205)$ from $1.9 \pm 4.28 \%$ (control) to a maximum of 10.24 $\pm 3.43 \%$ in all doses evaluated $(1.025,1.031,1.037$ and $1.043 \mathrm{mg} / \mathrm{g}$ ) (Figure 2C) and biochanin A showed similar results (Figure 2D).

Only the intermediate concentration of $2.3 \mathrm{mg} / \mathrm{g}$ was statistically significant to the control and all other doses tested, reaching a significant weight increase of 10.58 $\pm 2.69 \%$. The rest of the doses and the control did not differ significantly $(p>0.05)$.
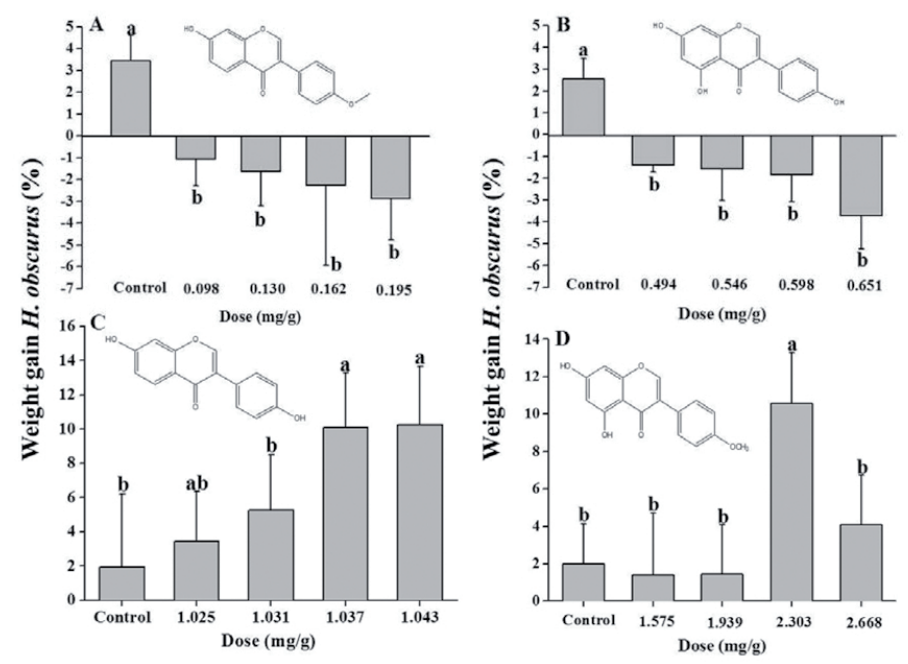

Figure 2. Weight gain (\%) of Hylastinus obscurus feeding bioassays using artificial diet. Treatment: A) formononetin $(0.098,0.130,0.1626$ and $0.195 \mathrm{mg} / \mathrm{g}), \mathrm{B})$ genistein $(0.494,0.546,0.598$ and $0.651 \mathrm{mg} / \mathrm{g})$, C) daidzein $(1.025,1.031,1.037$ and $1.043 \mathrm{mg} / \mathrm{g})$ and D) biochanin $\mathrm{A}(1.575,1.939,2.303$ and $2.668 \mathrm{mg} / \mathrm{g})$. Control = artificial diet. Different letters indicates significant differences between treatment and control by the non-parametric Kruskal-Wallis test followed by Conover-Inman test. 


\section{Discussion}

In general, forage legumes such as T. pratense produce phytoestrogens mainly belonging to the isoflavone group. Isoflavonoids are known to mediate plant-insect interactions, either deterring or stimulating insect feeding behaviour (Simmonds, 2003). For red clover, Saviranta et al., (2010) previously reported that the most abundant phenolic compounds in field-grown roots were the maleate glycoside of formononetin (3.90-4.27 $\left.\mathrm{mg} \mathrm{g}^{-1}\right)$, maackiain (2.35-3.02 $\mathrm{mg} \mathrm{g}^{-1}$ ) and pseudobaptigenin (1.80-2.58 $\left.\mathrm{mg} \mathrm{g}^{-1}\right)$, and the concentration of formononetin-aglycone was approx. $0.5 \mathrm{mg}$ $\mathrm{g}^{-1}$. Similar to that study, our work identified here 4 flavonoid aglycones (Table 1, Figure 1) in the polar extract of red clover roots. The level of formononetin found in Superqueli INIA $\left(0.195 \pm 0.1 \mathrm{mg} \mathrm{g}^{-1}\right)$ cultivar was similar to those reported by Saviranta et al., (2010), and formononetin (2) levels differed considerably between Quiñequeli INIA $\left(0.098 \pm 0.01 \mathrm{mg} \mathrm{g}^{-1}\right)$ and Superqueli INIA. However, the highest content of formononetin were found in roots of red clover (cv. Bjursele) samples ranging from 5.0 to $6.0 \mathrm{mg} \mathrm{g}^{-1}$ of dry matter (Saviranta et al., 2008). The differences could be explained by different factors, such as seasonality, environmental and organ or part of plant used for the analysis (Saviranta et al., 2010). On the other hand, Papadopoulus et al., (2006) indicated that there is significant genetic variability for formononetin (2) content among red clover cultivars, and concluded that the selection of individual plant phenotypes for high formononetin (2) could be effective for cultivar improvement. Other authors have reported that variations in the levels of flavonoids, especially formononetin (2) is because this compound is found mostly in aerial part of the plant (leaves, flowers and stems) (Vetter, 1995). In this regard, several studies reported that different breeding programs have been successful in the selection of cultivars and experimental lines with high and low formononetin (2) content (Rumball et al., 1997). In relation to the bioactivity against insects of flavonoids, Iwashina (2000) reported that a wide variety of flavonoids have been used as feeding deterrents towards harmful insect by some plants. During the last few decades many flavonoids with deterrent or antifeedant effects against the grass grub Costelytra zealandica (White) (Coleoptera: Scarabaeidae), causing significant impacts on the persistence and productivity of improved pastures in New Zealand have been reported (Zydenbos et al., 2011). In total, 23 isoflavonoids isolated from roots of Fabaceae species Lupinus angustifolius and Lotus pedunculatus were evaluated, being genistein one of the responsible for the deterrent activity (Lane et al., 1987). In this sense, Gerard et al., (2005) informed that formononetin (2) ranging from 0.62 to $1.53 \%$ in dry matter in three cultivars of red clover, GF131, G27 and Pawera, acted as chemical defenses against the curculionid Sitona lepidus, suggesting that their distribution in forage legumes can be manipulated by plant breeding to improve root health. The isoflavones formononetin (2), genistein (1), and biochanin A (4) present in the leaves of Trifolium subterraneum $\mathrm{L}$. have been reported to exhibit a greater deterrent activity on the red-legged earth mite Halotydeus destructor (Tucker) (Acari: Penthaleidae) than the respective glycosylated isoflavones (Wang et al., 1998). In relation to this study, formononetin has been reported by Cook et al., (1995) as responsible for conferring defence to white clover roots against the stem nematode Ditylenchus dipsaci because its accumulation in the meristems. Furthermore, some flavonoid aglycones may affect other parameters in insects such as reduced growth rate, to extend the duration of both larvae instar and progeny. Lahtinen et al., (2004) reported that larvae of Epirrita autumnata (Lepidoptera: Geometridae) reduced the growth rate and prolonged the duration of their first instars because to the high content of the aglycone 5-hydroxy- 
4',7-dimethoxyflavanone (10 mg/g leaf dry weight). The progeny produced by Formosan subterranean termite, Coptotermes formosanus Shiraki (Isoptera: Rhinotermitidae) was significantly decreased at 30 days after the application of $50 \mu \mathrm{g}$ of biochanin A (4) and genistein (29.9 and 18.6\%, respectively) (Boué and Raina, 2003). Genistein also has been demonstrated as detrimental on the feeding behavior of the pea aphid Acyrthosiphon pisum Harris (Hemiptera: Aphididae) at higher concentrations $(\geq 1,000 \mu \mathrm{g} \mathrm{cm}$ 3) stopped completely the salivation and passive ingestion (Goławska and Łukasik, 2012).

Similar to the reports by Simmonds and Stevenson (2001) and Yu et al., (2003), our results demonstrated that independent of the doses of individual flavonoids, in our research, all the concentrations of formononetin $(0.098,0.13,0.162$ and $0.195 \mathrm{mg} / \mathrm{g})$ and genistein $(0.494,0.546,0.598$ and $0.651 \mathrm{mg} / \mathrm{g})$ were detrimental on feeding behavior of H. obscurus (Figure 2). Similarly, feeding studies have suggested that formononetin and biochanin A elicit a deter behavior from both clover root weevil (S. lepidus) larvae which feed on the roots, and adults which feed on the red clover leaves (Gerard et al., 2005). These results could be related to both higher persistence and better agronomic yields observed in Superqueli INIA than Quiñequeli INIA (Ortega et al., 2014).

Moreover, the isoflavonoids genistein (1) and daidzein, when exuded by the roots, are important signals to Rhizobium sp. bacteria for the establishment of root nodules where the bacteria reside and fix atmospheric nitrogen in a symbiotic relationship with the plant (Subramanian et al., 2006).

\section{Conclusions}

We evaluated 4 isoflavonoid aglycones: genistein (1), formononetin (2), daidzein (3) and biochanin A (4) in feeding bioassays with artificial diet. The first two aglycones elicited an antifeedant effect on $\mathrm{H}$. obscurus while daidzein (3) and biochanin A (4) elicited phagostimulant behaviour. In summary, this work establishes detrimental effect of the flavonoids formononetin and genistein on the clover root borer, H. obscurus. Our results suggest that these isoflavonoids present in the roots of red clover are responsible for the decreased gain in H. obscurus, suggesting that the higher formononetin content in SuperqueliINIA than Quiñequeli-INIA would explain the high persistence of Superqueli-INIA. This research demonstrates the usefulness of isoflavonoids present in T. pratense as natural controllers of H. obscurus. Our results cannot be extrapolated to field conditions, but constitute an important basis to carry out future experiments that evaluate the resistance of these plants with high contents of formononetin (2), and present a new opportunity for plant breeders.

This information, associated with cultural practices, could help farmers and breeders to reduce $H$. obscurus populations in grassland, where this curculionid constitute an important pest.

\section{Acknowledgements}

The authors would like to thank the Laboratorio de Química Ecológica of Universidad de La Frontera for providing the facilities and constant support throughout this research. Financial support for this research was supplied by FONDECYT (Project 1141245). Rothamsted Research receives grant-aided support from the Biotechnology and Biological Sciences Research Council (BBSRC) of the United Kingdom. 


\section{References}

Aguilera, A., Cisternas, E., Gerding, M., Norambuena, H. 1996. Plagas de las praderas. In: I. Ruiz (Ed.). Praderas para Chile. INIA-Estación Experimental Carillanca, Temuco, Chile, pp. 309-339.

Alarcón, D., Ortega, F., Perich, F., Pardo, F., Parra, L., Quiroz, A. 2010. Relationship between radical infestation of Hylastinus obscurus (Marsham) and the yield of cultivars and experimental lines of red clover (Trifolium pratense L.). Journal Soil Science Plant Nutrition. 10. 115-125.

Boué, S., Raina, A. 2003. Effects of plant flavonoids on fecundity, survival, and feeding of the formosan subterranean termite. Journal of Chemical Ecology. 29. 2575-2584.

Conover, W. 1999. Practical Nonparametric Statistic. Willey, New York.

Cook, R., Tiller, S.A., Mizen, K.A., Edwards, R. 1995. Isoflavonoid metabolism in resistant and susceptible cultivars of white clover infected with the stem nematode Ditylenchus dipsaci. Journal of Plant Physiology. 146. 348-354.

Faccoli, M., Schlyter, F. 2007. Conifer phenolic resistance markers are bark beetle antifeedant semiochemicals. Agricultural and Forest Entomology. 9. 237-245.

Farag, M.A., Huhman, D.V., Lei, Z., Summer, L.L.W. 2007. Metabolic profiling and systematic identification of flavonoids and isoflavonoids in roots and cell suspension cultures of Medicago sativa using HPLC-UV-ESI-MS and GC-MS. Phytochemistry. 68. 342-354.

Franke, A., Custer, L.J., Cerna, C.M., Narala, K.K. 1994. Quantitation of Phytoestrogens in Legumes by HPLC. Journal of Agricultural Food Chemistry. 9. 1905-1913.
Gerard, P.J., Crush, J.R., Hackell, D.L. 2005. Interaction between Sitona lepidus and red clover lines selected for formononetin content. Annals of Applied Biology. 147. 173-181.

Goławska, S., Łukasik, I. 2012. Antifeedant activity of luteolin and genistein against the pea aphid, Acyrthosiphon pisum. Journal of Pest Science. 85. 443450 .

Iwashina, T. 2000. The structure and distribution of the flavonoids in plant. Journal of Plant Research. 113. 287-299.

Lahtinen, M., Salminen, J-P., Kapari, L., Lempa, K., Ossipov, V., Sinkkonen, J., Valkama, E., Haukioja, E., Pihlaja, K. 2004. Defensive effect surface flavonoid aglycones of Betula pubescens leaves against first instar Epirrita autumnata larvae. Journal of Chemical Ecology. 30. 2257-2268.

Lane, G.A., Sutherland, O.R.W., Skipp, R.A. 1987. Isoflavonoids as insect feeding deterrents and antifungal components from root of Lupinus angustifolius. Journal of Chemical Ecology. 13. 771-783.

Manosalva, L., Pardo, F., Perich, F., Mutis, A., Parra, L., Ortega, F., Isaacs, R., Quiroz, A. 2011. Behavioral responses of clover root borer to long-chain fatty acids from young red clover (Trifolium pratense) roots. Environmental Entomology. 40. 399-404.

Ortega, F., Parra, L., Quiroz, A. 2014. Breeding red clover for improved persistence in Chile: a review. Crops \& Pasture Science. 65. 1138-1146.

Papadopoulos, Y., Tsao, R., McRae, K.B., Mellish, A.E., Fillmore, S.A.E. 2006. Genetic variability 
of principal isoflavones in red clover. Canadian Journal of Plant Science. 86. 1427-1428.

Quiroz, A., Ortega, F., Ramírez, C., Wadhams, L., Pinilla, K. 2005. Response of the beetle Hylastinus obscurus Marsham (Coleoptera: Scolytidae) to red clover (Trifolium pratense L.) volatiles in a laboratory. Environmental Entomology. 34. 690695.

Rumball, W., Keogh, R.G., Miller, J.E., Claydon, R.B. 1997. "Grasslands G27" red clover (Trifolium pratense L.). New Zealand Journal of Agricultural Research. 40. 369-372.

Saviranta, N., Anttonen, M., Von Wright, A., Karjalainen, R. 2008. Red clover (Trifolium pratense L.) isoflavones: determination of concentrations by plant stage, flower colour, plant part and cultivar. Journal of the Science of Food and Agriculture. 88. 125-132.

Saviranta, N., Julkunen-Tiito, R., Oksanem, E., Karjalainen, R. 2010. Red clover (Trifolium pratense L.) isoflavones: root phenolic compounds affected by biotic and abiotic stress factors. Journal of the Science of Food and Agriculture. 90. 418-423.

Simmonds, M. 2003. Flavonoids-insect interactions: recent advances in our knowledge. Phytochemistry. 64. 21-30.

Simmonds, M.S.J., Stevenson, P.C. 2001. Effects of isoflavonoids from Cicer on larvae of Helicoverpa armigera. Journal of Chemical Ecology. 27. 965-977.

Steiner, J., Alderman, S. 2003. Red clover seed production: VI. Effect and economics of soil $\mathrm{pH}$ adjusted by lime application. Crop Science. 43 . 624-630.

Sutherland, O.R.W., Russell, G.B., Bigss, D.R., Lane, G.A. 1980. Insect feeding deterrent activity of phytoalexin isoflavonoids. Biochemical Systematic and Ecology. 8. 73-75.
Subramanian, S., Stacey, G., Yu, O. 2006. Endogenous isoflavones are essential for the establishment of symbiosis between soybean and Bradyrhizobium japonicum. Plant Journal. 48. 261-273.

Tapia, S., Pardo, F., Perich, F., Quiroz, A. 2005. Clover root borer Hylastinus obscurus (Marsham) (Coleoptera: Scolytidae) has no preference for volatiles from root extracts of disease infected red clover. Acta Agriculturae Scandinavica, Section B. 55. 158-160.

Tapia, T., Perich, F., Pardo, F., Palma, G., Quiroz, A. 2007. Identification of volatiles from differently aged red clover (Trifolium pratense) root extracts and behavioural responses of clover root borer (Hylastinus obscurus) (Marsham) (Coleoptera: Scolytidae) to them. Biochemical Systematics and Ecology. 35. 61-67.

Toledo, D., Parra, L., Mutis, A., Ortega, F., Hormazábal, E., Quiroz, A. 2014. Influence of longchain fatty acids on weight gain of Hylastinus obscurus (Coleoptera: Curculionidae). Ciencia e Investigación Agraria. 41. 357-364.

Vetter, J. 1995. Isoflavones in different parts of common Trifolium species. Journal of Agricultural and Food Chemistry. 43. 106-108.

Wang, S., Ridsdill-Smith, T., Ghisalberti, E. 1998. Role of isoflavonoids in resistance of subterranean clover trifoliates to the redlegged earth mite Halotydeus destructor. Journal of Chemical Ecology. 24. 2089-2100.

Yu, O., Shi, J., Hession, A.O., Maxwell, C.A., McGonigle, B., Odell, J.T. 2003. Metabolic engineering to increase isoflavone biosynthesis in soybean seed. Phytochemistry. 63. 73-76.

Zydenbos, S.M., Barratt, B.I.P., Bell, N.L., Ferguson, C.M., Gerard, P.J., McNeill, M.R., Phillips, C.B., Townsend, R.J., Jackson, T.A. 2011. The impact of invertebrate pests on pasture persistence and their interrelationships with biotic and abiotic factors. Pasture Persistence - Grassland Research and Practice Series. 15. 109-118. 